\title{
On Comparison of Mechanisms of Economic and Social Exchanges: The Times Model ${ }^{\diamond}$
}

\author{
Gregory E. Kersten ${ }^{1}$, Eva Chen ${ }^{1}$, Dirk Neumann², Rustam Vahidov ${ }^{1}$ \\ and Christof Weinhardt ${ }^{2}$ \\ ${ }^{1}$ InterNeg Research Centre, Concordia University, Canada \\ 2 IISM, Universität Karlsruhe, Karlsruhe, Germany
}

\begin{abstract}
An e-market system is a concrete implementation of a market institution; it embeds one or more exchange mechanisms. The mechanisms are-from the economic point of viewdisembodied objects (models and procedures) which control access to and regulate execution of transactions. E-market systems are also information systems which are information and communication technologies artifacts. They interact with their users; have different features and tools for searching, processing and displaying information. This work puts forward an argument that the study of e-markets must incorporate both the behavioural economic as well as the information systems perspectives. To this end the paper proposes a conceptual framework that integrates the two. This framework is used to formulate a model, which incorporates the essential features of exchange mechanisms, as well as their implementations as IS artefacts. The focus of attention is on two classes of mechanisms, namely auctions and negotiations. They both may serve the same purpose and their various types have been embedded in many e-market systems.
\end{abstract}

- This work has been partially supported by the Natural Sciences and Engineering Research Council, Canada and the Social Sciences and Humanities Research Council, Canada. 


\section{Introduction}

E-markets are an important component of e-business that bring demand and supply for goods and services into balance. They are the meeting places for buyers and sellers who use exchange mechanisms to conduct transactions. Exchange mechanisms are market institutions providing sets of rules, which specify the functioning of the market and permissible behaviour of its participants. Mechanisms vary from catalogues, where requests and offers are posted, to negotiations, where the participants bargain over the conditions of an exchange, to auctions, where one side automates the process during which participants from the other side compete against each other.

The design of exchange mechanisms is the concern of economists. The economists' interest in market institutions or mechanisms emphasizes problems of social decision making of who shall get what resources. In their influential articles Hayek (1945) and Hurwicz (1973), formulated the resource allocation problem as an information aggregation problem. Because the valuation of different kinds of resources by individuals and organizations is typically private information, it is difficult for a planner to define the efficient allocation that secures the best use of resources by the society. To solve this social decision making problem, the economic planner needs to extract this dispersed knowledge of the individuals by setting the right incentives.

Economists became involved with the engineering of market institutions, which involves the specification of rules to control the exchanges and trade execution, since the 1990's (Roth 2002). The field of market design provides a mathematical framework with which the outcomes of particular mechanisms can be computed as equilibrium, and the mechanisms could be designed to induce socially optimal outcomes (Maskin and Sjöström 2002).

In recent years, the economists have adopted laboratory experiments to confront theory with empirical observations in their "toolbox" (Roth 1995; Smith 2003). These test-beds for running experiments abstract from the real world situations in order to isolate specific human decision-making behaviours (Friedman and Sunder 1994). Isolation is achieved by inducing the pre-specified characteristics in participants of the experiments via a specially designed incentive system. This experimental control entails that the participants' innate characteristics can be assumed away (Smith 1994) and the market institutions are typically implemented in a highly simplified form.

Behavioural economists typically have to embed market institutions in some kind of information systems (IS). While doing so, however, they make a deliberate effort to devoid the system of any features, which may contribute to its ease or difficulty of use or appeal. Research questions in economics usually address the relationships between different incentive structures and mechanism outcome or the selection of an optimal (i.e. revenuemaximizing) mechanism.

Viewed from a different perspective, e-markets are information systems deployed on the networks, which incorporate exchange mechanisms. As such, they are of interest to IS researchers, who study behaviors of the users, with a particular interest in explaining perceived usefulness, fit with the task, intention to use, as well as other important IS adoption-related factors (e.g., Goodhue 1995; e.g., DeLone and McLean 2003; Iivari 2005). Beginning with the technology acceptance model (TAM) proposed by Davis (1989) to the unified theory of acceptance and use of technology (Venkatesh, Morris et al. 2003), users' 
attitude and behavioural intention has been the predominant concern of is researchers. These and many other past studies aimed at the uncovering and gaining understanding into users' initial perceptions when exposed to a system, as well as changes in perception during system usage.

Within the IS community there are different views on conceptualizing information systems. They range from the consideration of an IS as a single, albeit complex, tool, to an artefact which can be studied only through the perceptions of its users, to formal models and algorithms (Orlikowski and Lacono 2001). The view of IS as primarily models and algorithms is similar to the one espoused by behavioural economists: in both cases what matters is the model or mechanism, its "packaging and embellishment" are not relevant. In contrast, the two other views focus on the visible and accessible features of an essentially "black-boxed" system and ignore its "internals". In particular, numerous experiments and studies on technology acceptance, task-technology fit and the unified theory of acceptance and use of technology consider information systems as artefacts which can be assessed solely based on their users perceptions. They focus on the users' perceptions of the system and results from their interactions with the system, rather than actual results which are of main interests for the economists.

In the past information systems were often single-purposed and difficult to use and modify. The recognition that systems are made up of many different components was not essential because their interconnections were fixed. Increasingly however, systems comprise both complementary and competitive components with partial and provisional connections which can be easily changed in order to adapt the system to the user's preferences and the task athand (Orlikowski and Lacono 2001).

Information systems are becoming increasingly ubiquitous. Many require little training due to sharing common graphical interface features, which contributes to their ease of use. Systems, which "power" such websites as eBay.com, Amazon.com or Google.com may be very complex, yet they are deployed and used with little effort on the part of their users. The trend toward making systems easier to use will continue with the emergence of the "software as a service" which composes services dynamically, as needed, by binding together several low-level services into a service required by the users (Turner, Budgen et al. 2003). From the IS perspective, this changes the very concept of a system, because the same system could have not only different "look and feel" for different users but also provide very different services. Increasing software flexibility and customisability poses challenges for IS research by shifting key questions from: "Will this system be adopted? Will it be used and useful? Is it easy to use? Does it fit the task?" to questions pertaining to the design and customization of the system so that it can be effectively and/or efficiently adopted, can be useful and easy to use, and can fit the task well.

E-market systems are the focus of this paper. They are information systems which are information and communication technologies (ICTs) artifacts. They interact with their users; have different features and tools for searching, processing and displaying information.

An e-market system is a concrete implementation of a market institution; it embeds one or more exchange mechanisms. The mechanisms are-from the economic point of viewdisembodied objects (models and procedures) which control access to and regulate execution of transactions. The particular way of mechanism implementation of the employed technology is typically of little interest to economists. This neglecting of technology and implementation details stems from the belief that the use of a mechanism depends crucially on the incentive structure innate to the mechanism. On the other hand, much of is research 
is concerned with the implementation details and their impact on the use of a system. Because IS researchers are interested in gaining a glimpse into the reality irrespectively of its degree of complexity or messiness, they make an effort not to affect the experiment with any form of an incentive structure.

This work puts forward an argument that the study of e-markets must incorporate both the behavioural economic as well as the information systems perspectives. To this end the paper proposes a conceptual framework that integrates the two. This framework is used to formulate a model, which incorporates the essential features of exchange mechanisms, as well as their implementations as IS artefacts. The focus of attention is on two classes of mechanisms, namely auctions and negotiations. They both may serve the same purpose and their various types have been embedded in many e-market systems (Neumann, Benyoucef et al. 2003).

In the proposed research model five constructs are recognized: task, individual, mechanism, environment and system. The interaction of these constructs results in the subjective and objective outcomes, which describe the process and results of the transaction.

The purpose of the model, called TIMES model, is twofold:

1. Support the analysis of exchange mechanisms and their impact on human behaviour; and

2. Investigate the possibility of developing the prescriptive framework for advocating exchange mechanisms depending on the participants and their objectives, context and the exchanged object(s).

The remainder of the paper is structured as follows. In Section 2 two exchange mechanisms: auctions and negotiations are discussed and their hybrid forms are introduced. Sections 3 and 4 review the two perspectives on e-market design, namely those of economics and IS. Section 5 proposes an integrated framework for assessing e-market systems that incorporates the two perspectives. Section 6 concludes with a summary and an outlook on future work.

\section{Auctions and negotiations}

A market mechanism is understood here as a set of rules governing the transaction process, which defines how the market participants reach their agreements. Those rules can be understood as mechanisms, because they make behaviour more orderly and thus more predictable. Better predictability of counterparties' actions amounts to a reduction in transaction costs (Kiser and Ostrom 1982). The space of potential market mechanism is large, since there are many ways to define the rules which can be imposed on the exchange process. While the commonly used catalogue-based exchanges (i.e. take-it-or-leave-it mechanism) is one example of an institution, of greater interest to the researchers are classes of mechanisms, which permit richer dynamics and more complex behaviour on part of the market participants, e.g. auctions and negotiations (Wolfstetter 2000).

\subsection{Auctions}

Auctions are a class of mechanisms, which are used to determine the allocation of goods between sellers and buyers. They can be either single-sided, where one seller auctioneers off 
goods to a number of bidders, or double-sided, where competition is employed on both sides of a market. In recent times, auctions and their design have gained a considerable interest, because they have been widely used in practice to allocate products as varied as securities, offshore mineral rights and emission certificates (Wolfstetter 1995; Lucking-Reiley 2000).

Auctions are defined by an explicit set of rules which determine resource allocation and prices on the basis of the bids made by the market participants (McAfee and McMillan 1987). The four following characteristics differentiate auctions from other exchange mechanisms:

1. Auction rules are explicit and known to bidder prior to the auction. Therefore, rules cannot be modified during the auction.

2. The rules completely describe the mechanisms allowing for the determination one or more winners solely based on the bids. Auctioneers or any other party have no discretion in winner choice.

3. Rules typically include: (a) bidding rules stating how bids can be formulated and when they can be submitted; (b) allocation rules describing who gets what on the basis of submitted bids; and (c) pricing rules stating the corresponding prices the bidders have to pay (Reiter 1977); and

4. Auction rules allow mapping of bids on a single dimension - the price. Auctions focus on prices to achieve either an efficient allocation or revenue maximization.

The adequateness of utilizing the price mechanism has been conjectured by Hayek (1945) and has been demonstrated under certain assumptions by Hurwicz (1973). If those assumptions are violated (e.g. there are externalities in preferences), then richer message spaces, e.g. inclusion of delivery schedules and quality in addition to prices, may become necessary (Mount and Reiter 1974).

Modern auction theory has adapted to these needs of richer message spaces by including other than price attributes (Bichler 2000). A number of multi-attribute auctions and combinatorial auctions have been designed but have not been used because of their complexity in formulating strategies, eliciting valuations for combinatorial goods, solving the winner determination problem and communicating bids (Parkes 2001). Most auction formats still rely on a single price dimension.

Auction mechanisms dominate the economic view. In fact, the field of market design is almost exclusively focussed on the theoretical and applied auction theory. This focus has a major ramification upon practical market design: the decision whether to use auctions or other exchange mechanisms favours auctions.

\subsection{Negotiations}

Negotiation is a rich and ill-defined family of processes, used for exchanging goods or services among buyers and sellers, and resolving inter-personal and inter-organizational conflicts. Negotiation is an iterative communication and decision making process between two or more participants who cannot achieve their objectives through unilateral actions. In addition, negotiation involves exchange of information comprising offers, counter-offers and arguments with the purpose of finding a consensus (Bichler, Kersten et al. 2003). 
This notion of negotiations includes negotiation as an exchange mechanism, mediation, voting and other forms of conflict resolution. Restricting the attention to trade negotiations only, in which the participating agents engage in order to reach an agreement about an allocation (which goods are exchanged to whom at what compensation), simplifies negotiations to bilateral and multi-bilateral encounters in which two roles are distinguished: buyers and sellers.

The peculiarity of negotiation as an exchange mechanism is its degree of freedom in the level of structuring the process. Negotiations differ in the degree of their structuredness, possibility of modification, and participation rules (Bichler, Kersten et al. 2003; Ströbel and Weinhardt 2003). The process of interactions may be not prescribed a priori as it is the case with many face-to-face negotiations; and the rules may be known only implicitly, for example, based on tradition. Negotiations typically allow for the modification of the protocol, but this characteristic may be limited in the case of e-negotiations. Also, the participation may be limited or determined by one part allowing another to participate or not.

The above indicates the degree of flexibility in the design of negotiation mechanisms and this is the key characteristic that differentiates them from auctions. A particular instance of multi-bilateral negotiation can be indistinguishable from an auction, with offers having the same format as bids and forbidden exchange of arguments and other messages. The difference is that every negotiation allows for a change of its protocol while this is not allowed in auctions; instead one auction would need to be cancelled and a new one initiated.

Negotiations mechanisms have been studied in economics and game theory. For example, bilateral bargaining models were used to investigate how the surplus of a transaction is allocated between two parties (Nash 1954). They are typically used to analyze classes of cases, such as wage negotiations between unions and management. Recently, in response to the evolution of e-marketplaces, two streams of bargaining models have been studied in the field of economics in order to explain market behaviour. In the first stream of studies several bilateral bargaining processes between buyers and sellers have been investigated in order to determine the properties of the aggregate market, which results from the bilateral relationships (De Fraja and Sakovics 2001; Satterthwaite and Shneyerov 2003). One extension of this mechanism is a double-multi-bilateral negotiation in which one party (e.g. a buyer) negotiates with several sellers and each seller negotiates with several buyers. Such negotiations are similar to double-side auctions, but buyers are engaged in bilateral negotiations with many sellers and sellers are negotiating with many buyers (Satterthwaite and Shneyerov 2006). The second stream of empirical research extends bilateral bargaining models to multilateral bargaining (Thomas and Wilson 2002). The latter are similar to single-sided auctions in that they incorporate explicit competition among all participants representing one side.

\subsection{Hybrid forms}

Auctions and negotiations are considered here as two distinct classes of market institutions. The popularity of on-line auctions led some researchers to state that internet negotiations are auctions (Kumar and S.I.F. 1999), thus indicating that there is no need for negotiation mechanisms, while others stated that e-negotiations should be replaced with on-line auctions (Segev and Beam 1999). These statements, contrasted with beliefs that negotiations differ from auctions in essence, may have been behind efforts to design mechanisms, which have certain properties derived from both classes of mechanisms. 
Some of the combined or hybrid mechanisms are well known, albeit little studied. For instance, the mechanism used in hiring normally involves first a sealed bid auction with candidates submitting their resumes and other supporting documents. In the second stage, a small group of the auction winners is invited for the interviews involving negotiations over salary and benefits. Teich, Wallenius et al. (2001) propose NegotiAuction, a mechanism generalizing the process of auction followed by negotiation (Leskela, Teich et al. 2006). A reverse process, in which multilateral negotiations are followed-if the parties agree to do so-by an auction is suggested by Shakun (2005). These exchange mechanisms are said to have a hybrid format.

Other types of hybrid formats occur in practice. For example, e-Bay auctions allow for inclusion of a "Buy-it now" option that is typical for a catalogue, while Alibaba (http://alibaba.com) combines catalogues with free-text communication between the buyers and sellers.

\section{Experimental and field studies}

We are interested in the assessment and comparison of e-market systems which includes both economic and IS perspectives. Economic studies focus on market mechanisms, their functioning and efficiency. The focus of IS studies is on the systems in which the mechanisms are embedded with-in most cases-little concern for the mechanisms themselves. This indicates that the two areas of research are complementary as we attempt to show through the discussion of the theoretical and experimental studies.

\subsection{Auctions and negotiations in economics}

Research by the economists into auction mechanisms can be found in several theoretic studies on single- and multi-attribute auctions. Interestingly, the empirical research provides no clear answer as to the superiority of one mechanism with respect to another. These results are one of the motivations for the model we present in Section 5, which could be used in more comprehensive comparative studies of both auctions and negotiations.

\subsubsection{Theoretical comparisons}

Bulow and Klemperer (1996) have shown in one of the first formal comparative studies that simple English auction with $N+1$ participating bidders always yielded higher revenue than a negotiation with $N$ participants. In essence, Bulow and Klemperer did not analyze a specific negotiation protocol, but rather referred to an "optimal" mechanism. Such mechanism denotes an abstract selling scheme, which is designed so as to maximize revenue of the seller. The implication is that a seller should "devote resources to expanding the market than to collecting the information and making the calculations required to figure out the best mechanism." (op. cit., p. 180).

This result does, however, hold only under fairly strong assumptions, e.g. attribute preference independence. For affiliated preferences for example, the Bulow-Klemperer (1996) result also holds when the seller's choice of the negotiation mechanism is restricted. If other assumptions are relaxed (regularity, symmetry, etc.) the result may not be valid any more.

In this respect Kirkegaard (2004) showed that a seller-offer bargaining game is more 
advantageous than an English auction when demand is discrete, i.e. has finite space, and the buyers are patient. In those cases, sellers prefer a bargaining protocol over an English auction. Furthermore, Kirkegaard (op. cit.) showed that when demand is continuous, an English auction can be improved by some kind of pre-negotiation.

Bulow and Klemperer's (1996) as well as Kirkegaard (2004) models focus on revenue as the only comparison criterion. If other objectives (i.e. allocative efficiency) are considered, then both models do not provide valuable insights. But even in terms of revenue, the decision whether to use auctions or negotiations crucially depends on the assumptions.

Both papers only refer to single-issue mechanisms, a comparison between auctions and negotiations that are capable of submitting several attributes beyond the price has not yet been undertaken. The reason for this can be in the fact that studies of auctions that consider more attributes have only been published recently.

Che (1993) and Branco (1997) initiated studies on the buyer's payoffs in the two-attribute (i.e., price and quality) auctions. The private information of buyers determining the utility can be represented in one dimension; this shortcut allows applying the auction design apparatus to these problems. More recently, Beil and Wein (2003) analyzed the problem of designing the multi-attribute auction. They were in particular concerned with finding a scoring rule to maximize buyer's utility.

\subsubsection{Laboratory and field experiments}

Thomas and Wilson (2002; 2005) conducted two experimental studies, in which reverse auctions were compared with multi-bilateral negotiations. ${ }^{1}$ In their most recent laboratory experiments, they noted that general superiority of auctions predicted by Bulow and Klemperer's (1996) was not supported by the empirical data. In multi-bilateral negotiations, a buyer solicits price offers from multiple sellers and then the buyer requests more favourable offers form the sellers who need to compete against each other. In their first experiment Thomas and Wilson (2002) compared multi-bilateral negotiations with firstprice sealed-bid auction. In the second experiment they (2005) replaced the first-price with the second-price (Vickrey) sealed-bid auction.

Thomas and Wilson (2002) observed that for the inexperienced buyers and sellers multibilateral negotiations with two sellers led to significantly higher prices than first-price sealed bid auctions. In the experiment with four sellers both mechanisms were found outcomeequivalent. In their second study, Thomas and Wilson (2005) observed that prices in second price sealed bid auctions exceed the prices generated in multi-bilateral negotiations, suggesting that this auction mechanisms is inefficient in the given experimental setting.

The two studies discussed above compared price-only auctions and negotiations. Therefore, it is surprising that in some experimental settings negotiations were found to be more efficient than auctions.

Many commercial and non-commercial transactions concern objects characterized by multiple attributes. Few are now supported electronically with multi-attribute auction

1 Thomas and Wilson use the term multilateral negotiation which, in negotiation literature refers to negotiation with multiple sites. The case they consider has only two sides (buyers and sellers) and the term multi-bilateral is more adequate. 
systems. Ongoing and future work in auctions and negotiation suggests an increase in their use in multi-attribute transactions. At present time, we are not aware of any comparative studies of multi-attribute auctions and negotiations. Therefore, we restrict our discussion to selected experiments with multi-attribute auctions followed by discussion of negotiation experiments.

The highly stylised information exchange in auctions makes it impossible for the sellers (buyers) to learn the preferences (needs, limitations) of the buyer (sellers). Therefore, much effort in multi-attribute auctions experiments has been devoted to the role and scope of preference revelation schemes. Bichler (2000) conducted several such experiments in which the bidders (sellers) were given the utility (value) function of the buyer. The results show that multi-attribute auctions do not provide substantial benefits over comparable singleattribute auctions. In other words, even with fully-revealed utilities the additional complexity outweighs the theoretical gains.

Koppius and van Heck (2002) conduct experimental studies on the impact of information availability on the mechanism efficiency. The information availability specifies the type of information that is given to whom, or when and how it becomes available to whom during the auction. They studied two types of multi-attribute English auctions: (1) with unrestricted information availability, in which suppliers are provided with the standing highest bid and the corresponding bidder as well as score or bid ranking of the most currently loosing bids; and (2) restricted information availability, in which the bidders are only informed about the standing highest bid and bidder. The experiments indicated that auctions with unrestricted information availability yield higher efficiency than auctions with restricted information availability.

Strecker (2004) analyzed the impact of preference revelation schemes on the efficiency of multi-attribute English and Vickrey auctions. He concluded that English auctions with revealed preference structure of the buyer are more efficient than Vickrey auctions, and English auctions with hidden preferences. Chen-Ritzo, Harrison at al. (2005) introduced a multi-attribute English auction, where only partial information about the buyer's utility function was revealed. They showed that this variant performs better in terms of efficiency than a single attribute (price-only) auction. This outperforming of the multi-attribute over the single attribute auctions holds even though the bids in the multi-attribute auction were far away from those predicted by the solution predicted by theory. Notably, complexity in the auction mechanism consumes some of the efficiency gains over price-only auctions. This observation however, contradicts with the findings reported by Bichler (2000).

Bajari, McMillan and Tadelis (2002) conducted empirical analysis of auctions and negotiations in the construction industry. They observed that the use of the exchange mechanism depends on the knowledge and complexity of the context and task (product). Negotiations have advantages if the specifications of the product to be traded are not welldefined a priori, which is often the case in this industry. Negotiations, unlike auctions allow for the discussion and clarification of the specifications. Not surprisingly, their empirical analysis also reveals that auctions perform poorly in terms of efficiency when changes in the product design need to be made after the transaction took place.

\subsection{Lessons learned form economic research}

The apparatus of economics has shed some light into the selection decision whether to employ negotiations or auctions. However, while the theoretical results are unequivocal, the 
results from experiments are inconclusive. The strength of economic approach to study market mechanisms lies in its formal approach to experiment design and conduct. The power of economic approach to market mechanisms and transactions is in its capability of abstracting the functions and mechanisms, removing interfering events and processes and focussing on the mechanisms' behaviour. This strength coupled with the focus on the mechanism design and efficiency may also be seen as a weakness, in particular if the mechanisms implementation and functioning is an issue. In particular, we consider here four issues of importance for our discussion.

1. Economics is interested in mechanisms and their economic properties rather than in their users. The concerns are to determine if a mechanism functions according to its design, what is its efficiency and what outcomes it produces given an assumed environment (e.g. preferences), which leaves out many relevant peculiarities of the users (e.g. beliefs, emotions).

2. One of the most persistent issues within behavioural economics is the representation of human behaviour. Traditionally economics begins with "the notion of homo economicus acting in a world with full information, independent decision making, polypolistic competition, transitivity, and fixed preferences" (Beckert 2003). It relaxes some of the assumptions in order to study the violations of perfect rationality, but does not consider the real decision-makers "messiness" (e.g, deviation from (bounded) rationality and adherence to various rationalities (Simon 1986)) making its results difficult to implement in e-markets.

3. The impact of the system in which an exchange mechanism is embedded is often ignored. ICT imposes additional rules on human behaviour and it changes the behaviour of the participating humans. The devotion of economics to analyze highly abstract mechanisms "with little or no concerns for practical application" (Palfrey 2001) diminishes the value of economic theory for assessing real-world negotiation and auction systems.

4. Economics largely focuses on price-only mechanisms. Only a few papers address negotiations or auctions that use multiple attributes in allocation. Neglecting multiattribute problems diminishes the applicability of economics in procurement and other settings, where the resources for sale are not specified from the outset of procurement process. Although advancements have been made in the area of multiattribute auctions but a comprehensive comparison with multi-attribute negotiations is still missing.

The few shortcomings mentioned here do not take away significant contributions of economics to market research. The discipline of information systems with its concern for peoples' perceptions, attitudes and feelings, may help introducing ICT to behavioural economics. Is may allow for a more comprehensive e-market framework which can be used for the assessment of auctions and negotiation systems, in addition to the assessment of the mechanisms embedded in them.

\subsection{Information systems research}

Information systems research has been concerned with systems in organizations and their impact on organizational performance. Because of the reported problems with is projects' completion in time and within budget, and the cancellation of over $25 \%$ of projects (quoted 
after Legris, Ingham et al. 2003, p. 191), the purpose of IS research is to "further knowledge that aids in the productive application of information technology to human organizations and their management" (ISR 2002). This focus on management and productivity led to numerous studies on the impact of systems on organizations and their members. This behavioural orientation relies heavily on other reference disciplines, including organizational behaviour, psychology and management.

Is, computer science and software engineering are three academic disciplines dealing with the computing area, that is, the design, development, implementation and use of software. The latter two disciplines focus on the theoretical and formal aspects of computing, information architectures, methods and tools for software development, security, etc. Research in computer science and software engineering is oriented to model or software construction often with little empirical validation. Tichy et al. (1995) surveyed 400 computer science papers published by the ACM which made claims that required empirical validation. They found that $40 \%$ of these papers had no empirical support at all. A similar result was obtained from a survey of papers published in IEEE journals (Zelkowitz and Wallace 1998). For the papers which provided empirical evaluation the prevalent forms were case studies and lessons learned.

In contrast, Glass et al. (2004) review of over 1,500 papers from the three disciplines shows that the IS papers are predominantly concerned with evaluative and descriptive research (76\%) with validation coming from field studies (27\%), laboratory experiments (16\%) and case studies (13\%). The reliance of IS research on human and social sciences and on empirical validation makes it suitable for the studies of e-markets. In this section three well known IS models are briefly discussed.

\subsubsection{Technology acceptance model}

The technology acceptance model (TAM) is one of the models most often used to explain the willingness of potential users to actually use an information system (Davis 1989). In this, as well as in other IS models technology is viewed as hardware, software, services and their combinations.

TAM was extensively tested empirically (see, Legris, Ingham et al. 2003 for a review) and several extensions have been proposed (e.g. Szajna 1996; Al-Khaldi 1999). The basic structure of TAM is given in Figure 1.

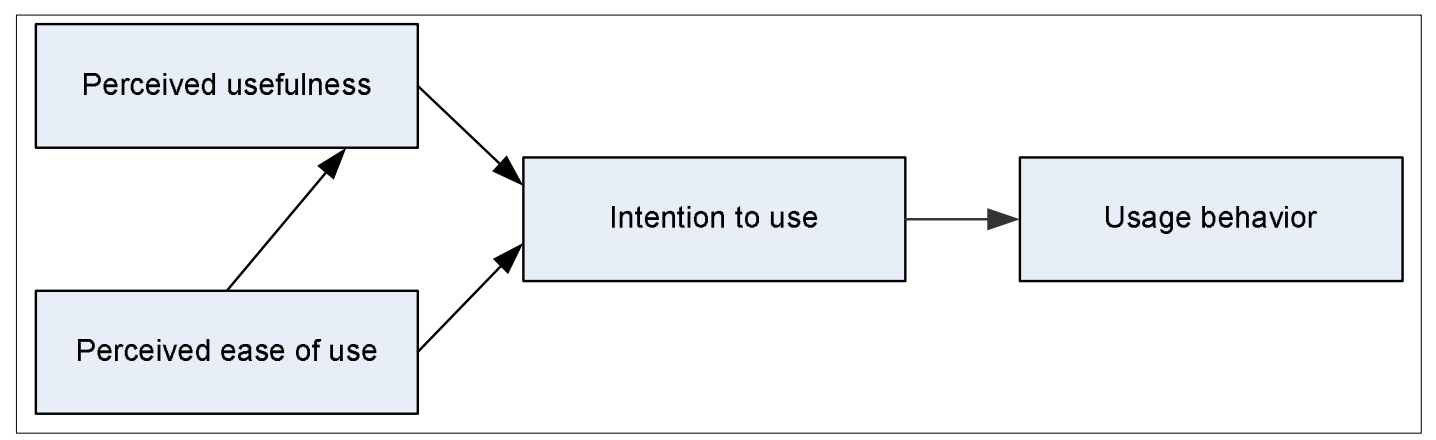

Figure 1: Technology acceptance model

According to the model, the actual use of a system is determined by the behavioural 
intention to use a system. This intention depends on the attitude towards the system, which is described by two subjective factors: the perceived usefulness and the perceived ease of use of the system. The model and the research instruments constructed within its framework have been found useful in studying potential and actual information system adoption and use in organizations (e.g. Szajna 1996; Agarwal and Prasad 1997; e.g. Jackson, Chow et al. 1997).

More recently Vankatesh and Davis (2000) proposed TAM2, which adds social norms to TAM. The extended model had been tested in field studies and the authors found that social norms and perceptions significantly influence user acceptance of technology. It should be noted, however, according to meta-analyses and field studies, both versions explain about $40 \%$ of the system's use (Agarwal and Prasad 1997; Venkatesh and Morris 2000; Legris, Ingham et al. 2003)

\subsubsection{Task-technology fit model}

Technology may me accepted and used, and yet fail to bring forth expected changes. Goodhue and Thompson (1995) proposed the task-technology fit (TTF) model designed to measure the impact of the technology on individual performance. The model (see Figure 2) considers tasks, which are activities requiring application of knowledge; they involve synthesis, assessment, problem solving and decision making. It asserts that individual performance depends on the fit between the task a user needs to undertake and the technology used for this task (Goodhue 1995).

The fit between task and technology is "the matching of the functional capability of available information technology with the activity demands of the task at hand." (Dishaw and Strong 1996). The better the fit is the higher user performance and, thus value of the technology. The model also includes the moderating role of user's characteristics on the user assessment of the task-technology fit.

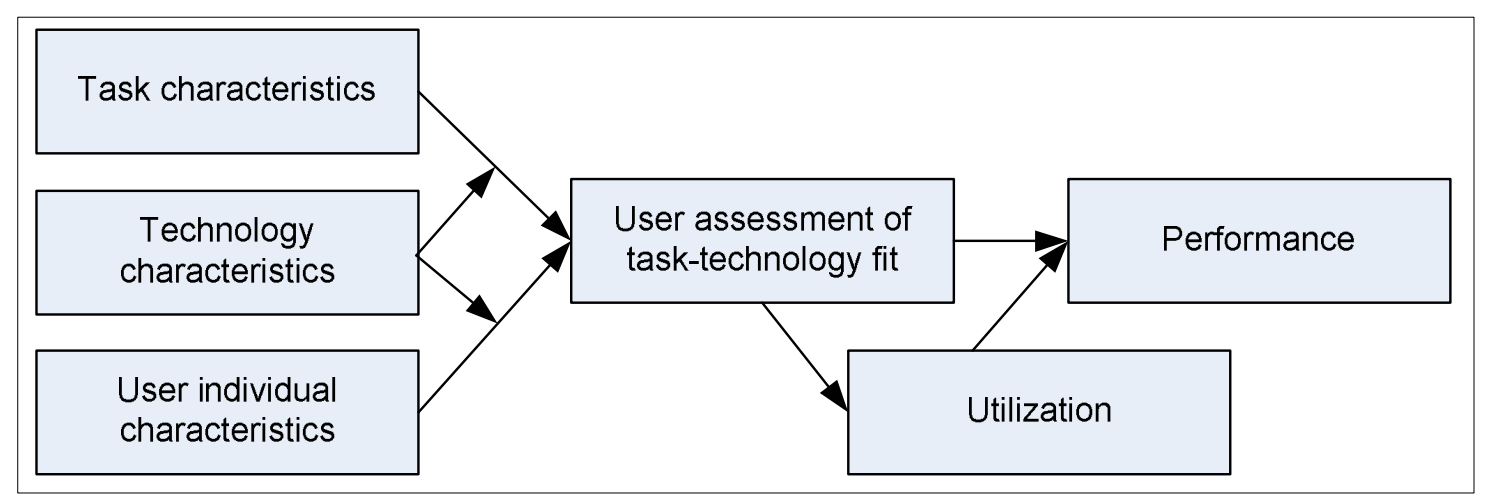

Figure 2. Task-technology fit model (based on Goodhue and Thompson 1995).

The TTF model, like many other IS research models, considers technology as complete computer systems (hardware software and data) as well as organizational is policies and services (Goodhue and Thompson 1995, p. 216). While the individual characteristics of the user (e.g., education, training and experience) are distinguished, the technology is blackboxed and no specific features, tools and mechanisms are included. System characteristics include data quality, ability to retrieve and consolidate required data and reliability. They are 
important but their assessment provides little insight regarding system adaptation and modification.

The model shares its subjective orientation with TAM and other models; it models user attitudes and behaviours toward the system (Dishaw and Strong 1998). The measurement of fit, utilization and performance are based on the user beliefs rather than any objectively measurable variables pertaining to cognitive effort, costs, time or productivity.

\subsubsection{DeLone-McLean model of information system success}

The TAM, TTF and other early models could have been used to study almost any technology. Although developed within the IS field, they do not consider the specific characteristics of software and make no distinction between software, hardware and services of the IT departments. The end user computing satisfaction (EUCS) model (Doll and Torkzadeh 1988) and the information systems success (ISS) model (DeLone and McLean 1992; DeLone and McLean 2003) explicitly consider the attributes of information and system which produces information.

The purpose of EUCS is to measure satisfaction of is users through the measurement of five variables describing information content, accuracy and format, and the system ease of use and timelines in producing data. The model has been widely used and considered as one that is principally connected to the IS field with the premise that this field differs from social and cognitive psychology (Doll and Torkzadeh 1991; Pikkarainen, Pikkarainen et al. 2006).

The ISS model, depicted in Figure 3, was designed to explain the key factors that are accountable for the success of information system projects. The key feature of the model is the separation of the quality of information provided by the system from the operational measures of quality of a system. The former includes such measures as information accuracy, precision, timeliness, and relevance, while the latter refers to such indicators as reliability, response time, and ease of use.

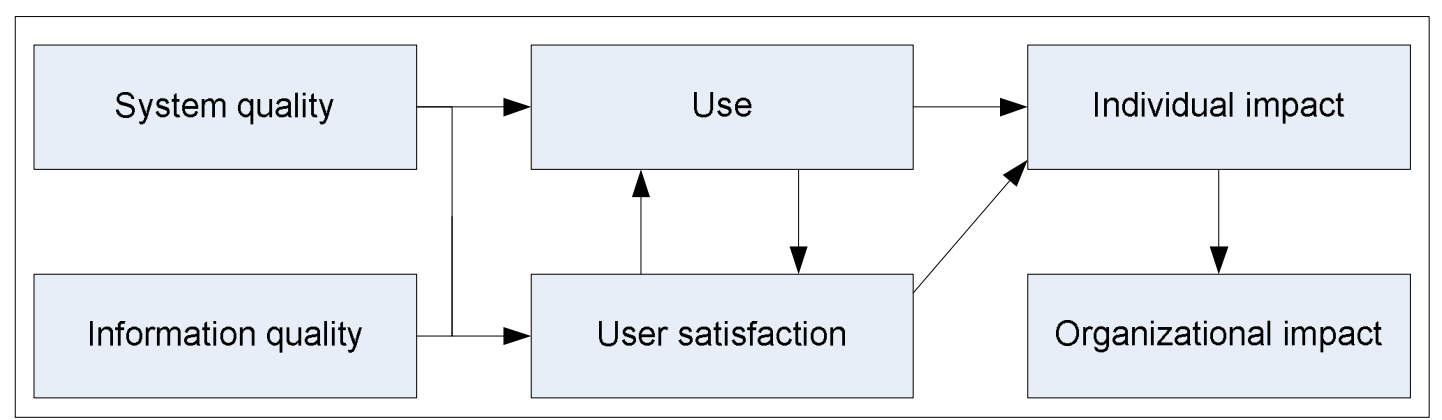

Figure 3. DeLone-McLean model (based on Iivari 2005, p. 10)

The model aims at predicting the individual and organizational impact of the system based on the attitudes formed by its users. The key factor conveying the attitude is user satisfaction. According to the model user satisfaction is influenced by the two essential quality-related factors of the system. Satisfaction has a significant impact on the actual system use, and the latter reciprocally affects the level of user satisfaction. Both of these constructs (use and satisfaction) affect the construct of individual impact, which in turns influences the organizational impact. 


\subsection{Lessons learned from information systems research}

The major focus of IS research has been on the attitudes and behaviours induced by the use of instantiated systems in organizations. This perspective brings in the psychological, organizational and social factors into the study of the impacts of information systems. The variables that describe subjective perceptions and aim at the facilitation of adoption of information systems and their impact on the individuals and organizations have been identified. These findings help explain how people perceive systems and which variables help successful adoption of systems by the users.

Behavioural models discussed in the preceding section and their various refinements are largely concerned with technology use, adoption, efficacy and satisfaction of its users. They are less concerned with the issues pertaining to the identification of the concrete features and aspects of IS artefacts. They are also less concerned with the identification of types of users, decision problems and organizations that are particularly (un)suitable for a given technological solution.

In this respect, it is worthwhile mentioning recent important concerns raised by the prominent researchers in the field. The first one concerns the diversity of themes in IS research and venturing by the researchers into the areas remotely related to the information systems (Benbasat and Weber 1996). These tendencies, according to the authors are undermining the very identity of the IS field (Benbasat and Zmud 2003). The authors stress that the research should focus on the phenomena intimately linked with the core subject of the field, which is information systems. On the other hand, another important, and possibly related issue is that of relevance vs. rigor. It has been stressed that IS researchers tend to overemphasize the rigor in conducting research, while largely sacrificing the relevance of the studies (Benbasat and Zmud 1999). In our view, the incorporation of system features in theoretical models could help tackle both of these issues. Firstly, the IS artefact would become an organic part of these models, thus battling the "identity crisis". Secondly, this would enable illuminating better design decisions during system development, as the theoretical findings will provide direction and support as to which salient features and functionalities to incorporate for a given class of contexts.

In light of approaching the study of techno-economic systems there are several issues which need to be considered in constructing prescriptive rather than descriptive models, which are focussed specifically on the ICT technologies and their configurations.

1. Presumably, technology is the focus when one tries to identify its usefulness, ease of use and its other user-oriented attributes. However, in many is models technology is not specified or even broadly defined. Models such as TAM and TTF can be applied to, for example, computing devices as well as to transportation apparatus. There is nothing that allows for the identification of the special nature of information systems viz. some mechanical systems.

2. IS researchers have focused on instantiated systems in the past and paid little attention to abstract features and models (e.g. mechanisms). This effectively restricted the possibilities of incorporating the characteristics of systems in theoretical models. While the IS success model does include the informational and system qualities, it does not provide sufficient insight into the drivers of IS quality, e.g. whether it derives from the model embedded in the system, or the way the model has been implemented in the system. It could be beneficial to separate the concrete 
features of implemented systems (e.g. user interface) from more abstract characteristics of the underlying mechanisms.

Is literature tends to underestimate the value of the objective measures (e.g. outcomes) associated with the system use, paying more attention to the subjective factors. While the subjective categories (beliefs, attitudes, etc.) are undoubtedly of critical importance, we believe that they are intimately linked to the objective variables, especially when studying new economic institutions, like electronic markets.

\section{Mechanism and system design}

Electronic markets are economic entities, as well as information systems. On one hand, these markets rely in their deep structure on some family of abstractly defined economic mechanisms. On the other hand, they are systems composed of software and hardware, which expose their functionalities through specific features of user interface. Thus, the theories that would usefully allow researchers to assess, compare, and prescribe e-market systems must include both economic and Is perspectives. One important question arising in connection with the possibility of such integration is how the issue of mechanism/system design is viewed in economics and IS.

\subsection{Basic concepts and theory building}

Market design in economics traditionally uses axiomatic models to obtain propositions and theorems about the impact auctions have on resource allocation. Unlike other areas of economics, market design has breed out a well-accepted methodology for designing and analyzing auctions. In recent times, laboratory experiments and numerical simulations have been added to complement the study of auctions (Roth 2002).

A framework for economic market design research has been proposed by Smith (1982; 2003), who sought to reconcile theoretic research with laboratory experiments. The framework is so general that it applies to any microeconomic system. In essence, Smith suggests that the analysis of alternative exchange mechanisms always share a common view on the structure of the microeconomic system (Hurwicz 1973; Reiter 1977). The framework sketches an economic system comprising economic environment, individual preferences, behaviour, mechanism, outcomes and performance (see Figure 4). 


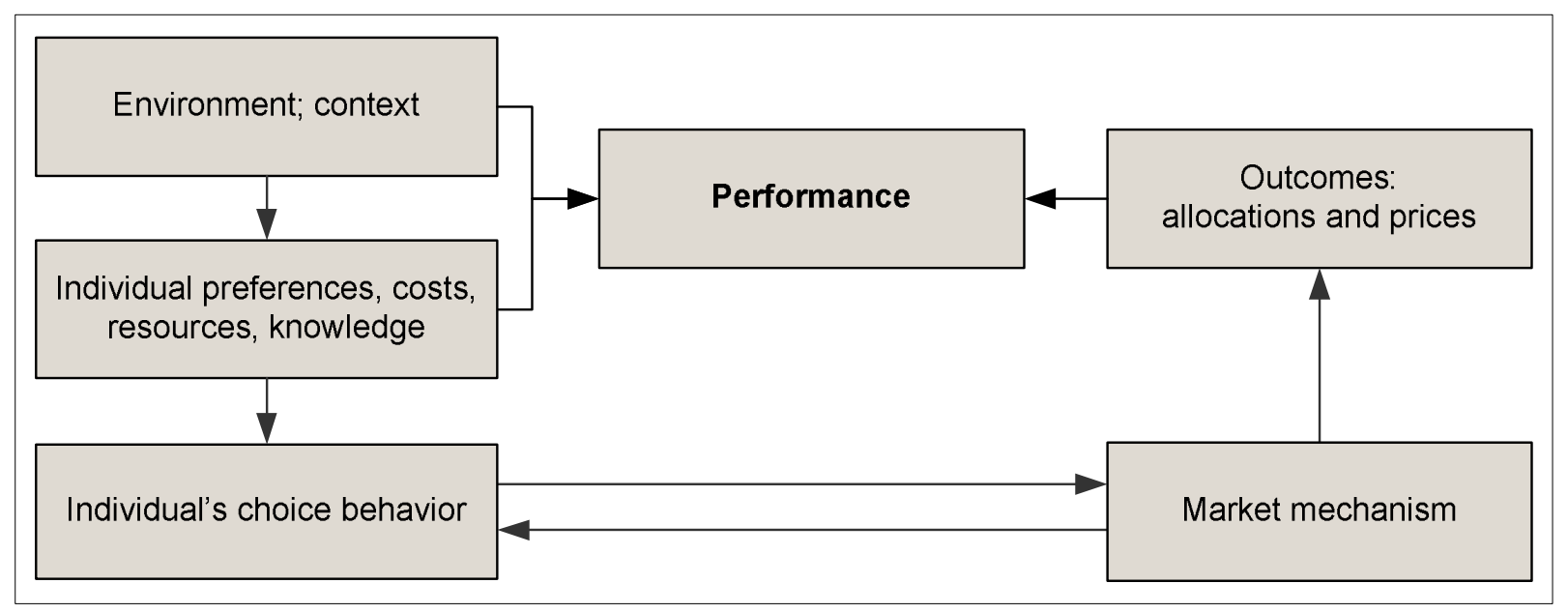

Figure 4: Microeconomic system framework (adapted from Smith 2003)

The economic environment describes all factors (e.g., legal regulations, types of products and services, customs and social norms), which influence demand and supply in which economic agents (individuals) operate. These factors are out of direct control of the mechanism designer. Deviating from Smith's depiction, we distinguish two parts of the environment, the context and the individual characteristics.

The context characterizes the situation, in which the resources are being allocated. For example, the context may describe a procurement setting with multiple sellers competing against each other to serve one buyer. Economic theory attempts to eliminate context by abstracting the resource allocation as much as possible.

The individual (economic agent) is described by all characteristics relevant to the decision making, that is, his or her concrete choices. The key characteristics are preferences, risk attitude, costs, resources (endowment) and knowledge.

The individuals' characteristics are affected by the context, in which they operate. Their actual preference structure and other characteristics determine their choice behaviour. The individual's choice behaviour impacts, in turn, the functioning of the exchange mechanism.

The market institution is the set of rules and formulae which specify the way offers (bids, proposal) can be formulated and how they are translated into outcomes (i.e., allocation and prices). In other words, it is fed inputs (offers) and yields as its output an allocation of resources among the participating users. The institution can be seen as a dialogue between its users leading to an allocation of resources.

Individual choice behaviour does not depend solely on the individual and the environment she or he operates in. The behaviour is considered here a middle layer between the motivations of individual buyers and sellers embedded in their local environment and the feasible actions confined by the market institution and the resulting outcomes. Within the boundaries of the institution the participating users need to formulate their needs in terms, which are acceptable by the mechanism. Therefore, market institutions restrict the users' response behaviour, without uniquely prescribing it (Hurwicz 1973). 
The outcomes of the use of the mechanism by individuals are the allocation of the resources among the individuals and the corresponding prices which they pay. The environment consisting of the context and individuals - directly affects the performance of the mechanism.

Performance is determined by the outcomes, the environment and the mechanism users. The performance is of the mechanism rather than its users; it is defined by the comparison of the outcomes with those achieved when other mechanisms are employed.

This framework aggregates all factors that are relevant for studying mechanisms. As aforementioned, the framework captures both streams of market research, the mechanism design stream, on the one hand, and the stream of laboratory experiments, on the other hand (Smith 1982).

The mechanism design problem can be formulated as the identification of a mechanism such that the equilibrium outcome satisfies the desired performance expressed by an evaluation function. The evaluation function values the outcome attained by the mechanism in a specific environment. This formulation is rather general, as it regards not only the preferences of the individual, but also all other possible arguments of the environment. Mechanism design seeks to describe mechanisms, which maximize the evaluation function subject to three types of constraints: (1) incentive compatibility constraints; (2) computational compatibility; and (3) the constraints imposed on participation.

The incentive compatibility constraints require that the participants truthfully report their information about their local environment. In such a case, the outcome is the same as if a benevolent arbitrator would have chosen the outcome on the basis of the full information about the environment. The computational compatibility constraints refer to the complexity of the outcome function. Outcome functions can be very demanding concerning computational tractability (Rothkopf, Pekec et al. 1998). The computational compatibility constraint assures the feasibility of the applied outcome function. The participation constraints require that the participants voluntarily take part in the mechanism's use. The individuals participate if the benefit they draw out of participation is higher than participation in an alternative mechanism (Ledyard 1993).

In laboratory experiments, both the environment and the institution are controlled by the experimenter. Achieving control over institution is in principle very straightforward, as the experimenter not only explains the institutional rules but also enforces them. Achieving control over the environment is less easy, as the humans who participate in the experiment have idiosyncratic characteristics that are unknown to the experimenter (and can hardly be observed). If the experimenter wants to examine theories that rely on certain assumptions on the characteristics of the individuals, the experimenter has to align the unknown characteristics of the individual with the assumed behaviour. This is particularly challenging as these two can fundamentally differ from each other.

Experimental economics usually employs induced values. By coupling behaviour with a rewards scheme the experimenter attempts to induce the values upon the individual, overruling the real characteristics. Since it is very difficult to control the context, experimenters frequently try to abstract from the context as much as possible.

As a consequence of this approach, in many cases laboratory experiments test theory, whereas the exploration of new mechanisms under real world is increasingly neglected. 


\subsection{Design research in IS}

The problem of systems analysis and design has long been one of the core subjects of study in the area of information systems. Considerable attempts have been made in the past in developing methods, techniques, and tools for guiding the development of concrete systems. However, the study of the IS design is a relatively recent and gaining popularity and consideration of an important part of IS research (Gregg, Kulkarni et al. 2001; Markus, Majchrzak et al. 2002; Dufner 2003; Hevner, March et al. 2004).

Nunamaker et al. (1991) had argued that system development is an important research methodology to study information systems. They encouraged researchers to develop prototypes as means of better understanding the research domain, thus emphasizing the instrumental role of artifacts (i.e., the means) in IS research. Burstein and Gregor (1999) had proposed and defended the view of system development as a type of action research. They stressed that it can play an important role in theory building, experimentation, and observation. While these views put forward a model for IS research whereby IS artifact design is the means of conducting research, a stronger perspective treats the artifact itself as the end.

Herbert Simon's seminal book "The Sciences of the Artificial" had introduced the issue of design research in the computing disciplines (1996). One of the most significant insights by Simon was the separation of the outer environment from the inner environment of an artifact. The outer environment could be regarded as the requirements imposed on the artifacts' function. The inner environment is the internal organization of the artifact. Simon regarded design as the interface between the outer and inner environments of an artifact. March and Smith have shown that the design and natural science approaches in IS research should be complementary, whereby the design phase consists of building and evaluating IS artifacts, and the "natural science" phase with theorizing abut artifacts and justifying the theories (March and Smith 1995). According to them there are four types of products of design research, including: constructs (language), models, methods, and implementations (this included both prototypes as well as working systems).

Walls et al. (1992) proposed the notion of a "design theory" for information systems, in which they envisaged the use of "kernel theories" in the design of a class of artifacts. According to them design theories should consist of type of user requirements ("metarequirements"); type of system solution or class of artifacts ("meta-design"); and the type of methodology used to develop such artifacts. Thus, in this work they had explicitly emphasized the shift of focus from instantiated systems to the classes of artifacts. They had used an example of "vigilant executive information systems" to present an example of a design theory. More recently, Markus et al. (2002) employed this concept of a design theory to devise the characteristics of a broad class of systems that the authors called "systems that support emergent knowledge processes". In a recent publication Hevner et al. (2004) stressed the necessity of emphasizing rigor in conducting design research and advocated a number of guidelines for design researchers.

In summary, the most important contributions of the design research to the study of information systems include:

1. Approaching the design of IS artifacts as a legitimate and rigorous research initiative; and

2. Recognition that the IS artifact in the context of design research refers to classes of 
systems, rather than specific instantiations.

Together these principles help bridge the gap between the IS community on one hand and those interested in the design of markets and economic exchange mechanisms on the other.

\subsection{Convergence of IS and economics designs}

Notable attempts have been made in the recent past by the researchers in both fields to entertain the possibilities of adopting alternative perspectives to studying the core subjects of their respective disciplines. While information systems are engineered artifacts, engineering approaches seem to have wider applicability in somewhat less expected areas. Roth (2002) have advocated an engineering view of economics and pointed at the emerging discipline of design economics: "the part of economics intended to further the design and maintenance of markets and other economic institutions" that would rely on the use of computational models and experimental approaches. Subrahmanian and Talukdar (2004) have discussed how market design can be formulated as an engineering problem.

Researchers in Is have started integrating economic perspective in their assessment of the utility and impact of systems, in particular those that support e-commerce applications (Zwass 1996; Bhargava and Sundaresan 2004; Zhu 2004). The recent discussion on the nature of the core of the discipline highlights important alternative models for conceptualizing information systems. Alter (2003) proposes and defends what he calls the IT-reliant work system view, where the emphasis is placed on the business and organizational processes as supported by the information systems, rather than focusing on purely technological aspects. El-Sawy (2003) advocates the adoption of the "fusion" perspective, according to which the IT artifacts have merged with the respective processes and entities in business environment to an extent that it is no longer possible to separate them from each other.

As it has been stressed earlier, design research aims at producing generic system solutions to practical problems, while preserving the level of rigor characteristic of other, more traditional modes of research. The type of system solutions proposed by a design researcher is a class of systems, or meta-systems (Walls, Widmeyer et al. 1992; Iivari 2003). According to one proposed representational framework, a researcher's view of an abstract IS artifact can be organized according to a number of perspectives (Vahidov 2006).

Following these lines of interdisciplinary study, in the next section we propose a unifying theoretical model that allows studying the impact of exchange mechanisms together with other contextual variables on the relevant dependent variables derived from the fields of information systems and economics.

\section{TIMES Model}

The advance of electronic commerce and new forms of technology-enabled exchange models brings together the fields of IS and economics closer than ever before (Zwass 1996; Bhargava and Sundaresan 2004; Zhu 2004). This de-facto merging of the structures of exchanges among participating economic entities and the types of evolving system solutions to facilitate such exchanges necessitates the development of novel research models to study the resulting forms of amalgamated mechanisms. Such models must necessarily integrate the existing theoretical frameworks from both perspectives. 


\subsection{Basic concepts and dependencies of the TIMES model}

The developments discussed in Sections 3 and 4 facilitate construction of a research model that draws on the theoretical constructs derived both from economics as well as Information System field. The relevance of these constructs has been studied in behavioural economics and IS. An integrated model puts forward relationships between the independent variables, including type of mechanism and contextual factors on one hand, and the performancerelated criteria on the other. The factors that have their origin in economics include mechanism, environment, and individual characteristics which drive the choice behaviour of the market participants ultimately resulting in certain outcomes.

The IS literature has been studying, among other phenomena, the effects of the system, individual, and task characteristics on the performance and on the subjective (perceived) assessments of the systems. In the integrated model proposed here the characteristics of: task, individual, mechanism, environment, and system-jointly called TIMES-are included as independent constructs.

For convenience, we will introduce the TIMES model, by pointing out the differences with the microeconomic system framework.

\subsubsection{From the economic environment towards task, individuals and (IS) environment}

Not only economic theories but also laboratory experiments too often define task complexity away (e.g. in the context of market design the determination of the bidding strategy) by assuming that people can determine an optimal strategy no matter how complex the task might be. However, humans tend to adopt simplifying strategies if the task is complex. They also may ignore complexity. For market design, this implies that the designed exchange mechanisms may be too complex for humans to derive the optimal strategies.

Complex negotiation tasks that require substantial cognitive efforts tend to lead to suboptimal solutions (Hyder, Prietula et al. 2000). People's cognitive limitations, their lack of interest in engaging in highly complex transactions, and their involvement with many competitive activities often lead to their selection of a quick and simple mechanism or tool which does the work even if the results are not optimal. Some may know that the use of a simple tool allows them doing more elsewhere; others may be unable of learning the tool's intricacies. This latter issue has been studied within the information system domain.

Having in mind the importance of the task, it appears reasonable to separate the task from the environment, where the task construct refers to the properties of the task that needs to be accomplished through the use of exchange mechanism. Rangaswamy and Starke (2000) provide the characteristics of bargaining orientation, degree of conflict, time pressure, and complexity for describing tasks.

The (IS) environment construct captures the environmental factors that may have impact on the negotiation outcomes, including type of market, type of product, level of competitiveness among buyers and sellers, and other important contextual considerations.

\subsubsection{From institutions to mechanisms and systems}

One lesson learned by the economics is that the institution matters. We use the term 
mechanism here to reflect the economic notion of institutions. The mechanism reflects the convergence point of institution construct from the economics perspective and meta-system from the IS perspective. Accordingly, the mechanism is an abstract artefact describing the protocol and mode of exchange regardless of its implementation. The description of the mechanism can be based upon the Montreal Taxonomy, which provides a comprehensive schema for classification of such mechanisms (Ströbel and Weinhardt 2003). The characteristics include, but are not limited to: flexibility, rounds, concurrency, number and nature of attributes of offers, offer matching, offer evaluation, and others. Additionally, the availability of analytical support (decision support capabilities) and mediation can be added for a useful description (Rangaswamy and Starke 2000). Taking only the mechanism into consideration is, however, not sufficient, as it abstracts away from the implementation and thus limits the consideration of subjective factors explaining its acceptance.

Different from economics, the TIMES model regards the way and form a mechanism is presented to its users, how it is embodied into a system, and, what is the interaction process between the system and the user to be a crucial construct. We know that the way problems are presented and the way people are prompted to make choices and solve problems, affects their behaviour. A mechanism has to be implemented in some medium; it has to communicate with the user using media. These are design issues and they are no less important for the mechanism, the outcomes and the performance than the mechanism itself. Thus, we include the construct "system" in our model. The system construct reflects those characteristics of the instantiated systems that are implementation-specific, including user interface, various features, and functionalities.

\subsubsection{From individuals' choice behavior to individual}

The individual construct refers to those aspects of individuals that tend to be relevant to negotiation process and outcomes, including: individual characteristics, number of users, as well as psychological issues such as attitude, beliefs etc. Here, the purpose is to explain the choices made by the individuals in light of their characteristics, and their interactions with the task, system, mechanism, and environment.

\subsubsection{From system performance to performance, ease of use, usefulness and satisfaction}

The assessment of performance used in the TIMES model is more complicated than the economic notion of performance. The dependent variables -partly being derived from IS research - are both of the objective as well as subjective or "perceived" nature. The former type seems to be emphasized in economics, while the latter has been the focus of extensive behavioural investigations in the area of information systems. The importance of subjective assessments lies in the fact that the latter tend to contribute towards the adoption of the systems by individuals. We have incorporated performance as an objective dependent construct in our model and (perceived) usefulness, ease of use, and satisfaction with the outcome as subjective variables.

\subsection{TIMES constructs}

The overall impact of TIMES variables on important dependent constructs is shown in Figure 5 . 


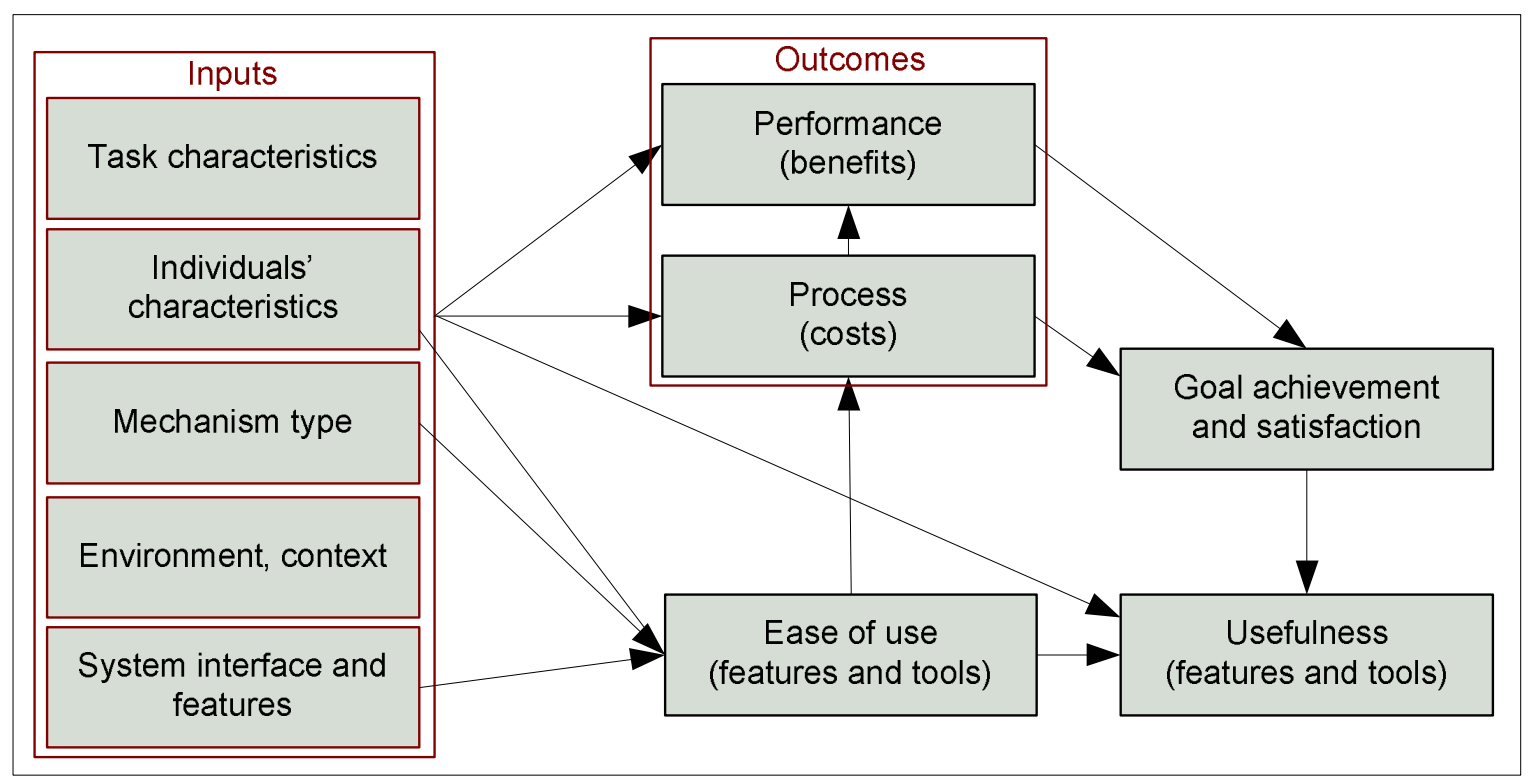

Figure 5. TIMES model.

As we have already introduced the TIMES variables, below we will elaborate on the choice of the dependent ones, as well as the impacts on them.

\subsubsection{Ease of use and usefulness}

According to the technology acceptance model (TAM), perceived usefulness and ease of use are important facotrs that could help predict actual usage of the system in question. The effect of ease of use on perceived usefulness had been postulated by TAM and has been widely studied (Davis 1989). Despite its popularity, the TAM model had been recently criticized for ignoring important variables related to system features (Wixom and Todd 2005). It has been noted that an alternative stream of research had been focusing on the way system features influence users' beliefs and attitudes, including, most notably user satisfaction (Baroudi and Orlikowski 1988; Doll, Hendrickson et al. 1998).

\subsubsection{Goal achievement and satisfaction}

A model integrating important object-based and behaviour-based beliefs had brought together the important theoretical constructs to provide a more comprehensive picture of system adoption (Wixom and Todd 2005). In this model satisfaction with the way the system provided informational support is positively related to the perceived usefulness of the system. Thus, we have incorporated satisfaction as a relevant predictive factor of the perceived usefulness. Since we are interested in both important objective (economics) as well as subjective (behavioural research in IS) factors our model postulates that the overall satisfaction will be influenced by the objective performance of individuals. Objective outcomes are nevertheless separated from subjective evaluations (satisfaction), since the recent study suggests that these do not necessarily behave identically in all cases (Galinsky, Mussweiler et al. 2002). For example, when high targets are stated, negotiators tend to be dissatisfied with the objectively superior outcomes. We also note that the satisfaction is individual while the outcomes not necessarily so (some depend on more than one person). 


\subsubsection{Outcomes}

The construct outcomes is decomposed into two types: (1) the costs required to achieve the final state (success or failure); and (2) the performance of the overall socio-economic system, that is the results achieved.

In the expanded model (Figure 7), some of the dependent variables (namely, performance, process and usefulness) are influenced by the combined effects of all of the variables on the independent side. According to the Task-Technology Fit perspective, (individual) performance is influenced by the degree of perceived fit between the characteristics of task, individual performing the task, as well as the technology used to carry out the task (Goodhue 1995).

Since the perceived fit construct is conceptually close to the concept of usefulness (of a particular tool for a particular task and individual), we postulate that the latter is influenced by the combined effect of the TIMES variables. Moreover, as noted earlier the economics view suggests that the environmental and individual characteristics lead to different outcomes in interaction with institutions. Thus, in our model performance is also influenced by the TIMES variables.

Furthermore, we expect that while satisfaction is affected by the objective performance, it will also be influenced by the individual characteristics of the users. Since ease of use refers to the reduced cognitive effort in using a system implementing a particular mechanism, we expect that the concrete features and interface of the system, the type of the mechanism that it implements, as well as individual characteristics will be the primary factors driving this perception. In addition, ease of use will be influenced by the objective characteristics of process induced by the use of a particular type of mechanism, embedded in the system and used for a specific task.

\section{Discussion and future work}

Electronic commerce has led to the emergence of the new forms of electronic exchange mechanisms driven by the convergence of economic and technological factors. The complexities of these formations preclude one-sided attempts to meaningfully study them from either side. Instead, a comprehensive approach to investigate the components and workings and guide the design of electronic markets demand an adoption of the integrated techno-economical frameworks of reference. The purpose of this paper has been to propose a model for studying the impacts of electronic exchange mechanisms on key variables of interests, both objective, as well as subjective ones. To this end we had reviewed and incorporated relevant concepts from both fields of Economics and Information Systems.

The proposed TIMES model provides a framework that allows studying of types of exchange mechanisms in their various implementations within different task, environment, and individual contexts. These mechanisms could range from the simplest catalogue-based models to advanced auction and negotiation schemas. Thus, the model can accommodate continuity in the key design principles of the mechanisms, as opposed to considering them as distinct classes. Therefore, one of the key contributions of the model is that it enables the comparison of various exchange structures in terms of the same set of key dependent factors.

One research project that will utilize TIMES to compare particular forms of auctions vs. negotiations has been briefly discussed earlier (NorA). This project will provide empirical 
data for testing the theoretical model, and provide key insights into the implications of design of market mechanisms for different classes of tasks. In particular, the key objective process and performance characteristics, as well as subjective perceptions and evaluations induced by adopting auctions vs. negotiations for specific tasks will be revealed. Comparisons of other relevant types of mechanisms within the TIMES framework will become the core part of future empirical efforts.

While the study of electronic exchange mechanisms has been the primary motivation for developing the TIMES model, we believe it is not limited to studying information systems for conducting market transactions only. It can be used to study also other information systems for which the issues of their ease of use, performance and usefulness are of interest. In this respect, the inclusion of the abstract representation of the underlying "mechanism" in addition to the concrete implementation-specific features would enable studying broad classes of systems. The proposed model thus could be potentially extended to become a powerful tool for the design research community, as the latter is focusing on developing innovative classes of systems. This extension of the TIMES model would however require to expand the notion of the mechanism towards the task. The emphasis of the mechanism (and algorithms) embedded in the system fundamentally affect the perceived usefulness of the system.

\section{References}

Agarwal, R. and J. Prasad (1997). "The Role of Innovation Characteristics and Perceived Voluntariness in the Acceptance of Information Technologies." Decision Sciences 28(3): 557-582.

Al-Khaldi, M. A. (1999). "The Influence of Attitudes on Personal Computer Utilization among Knowledge Workers, The Case of Saudi Arabia." Information and Management 36(4): 185204.

Alter, S. (2003). "18 Reasons Why IT-Reliant Work Systems Should Replace "The IT Artifact" as the Core Subject Matter of the IS Field." Communications of the Association for Information Systems 12(23): 366-395.

Bajari, P., R. McMillan and S. Tadelis (2002). "Auctions versus Negotiations in Procurement: An empirical analysis." Working Paper.

Baroudi, J. and W. Orlikowski (1988). "A Short-form Measure of User Information Satisfaction: A Psychometric Evaluation and Notes on Use." Journal of Management Information Systems 4(4): 44-59.

Beckert, J. (2003). "Economic Sociology and Embeddedness: How shall we conceptualize Economic Action?" Journal of Economic Issues 27(3): 769-787.

Beil, D. R. and L. Wein (2003). "An inverse-optimization-based auction mechanisms to support a multiattribute RFQ process." Management Science 49(11): 1529-1545.

Benbasat, I. and R. Weber (1996). "Research commentary: Rethinking "diversity" in information systems research." Information Systems Research 7(4): 389-399.

Benbasat, I. and R. W. Zmud (1999). "Empirical Research in Information Systems: The Practice of Relevance." MIS Quarterly 23(1): 3-16.

Benbasat, I. and R. W. Zmud (2003). "The Identity Crisis within the IS Discipline: Defining and Communicating the Discipline's Core Properties." MIS Quarterly 27(2): 183-194. 
Bhargava, H. K. and S. Sundaresan (2004). "Computing as Utility: Managing Availability, Commitment, and Pricing through Contingent Bid Auctions." Journal of Management Information Systems 21(2): 201-227.

Bichler, M. (2000). "An Experimental Analysis of Multi-attribute Auctions." Decision Support Systems 29(3): 249-268.

Bichler, M., G. E. Kersten and S. Strecker (2003). "Towards a Structured Design of Electronic Negotiations." Group Decision and Negotiation 12(4): 311-335.

Branco, F. (1997). "The Design of Multidimensional Auctions." Rand Journal of Economics 28(1): 63-81.

Bulow, J. and P. Klemperer (1996). "Auctions versus Negotiations." $\underline{\text { American Economic Review }}$ 86(1): 80-194.

Che, Y.-K. (1993). "Design Competition through multidimensional auctions." $\underline{\text { RAND Journal of }}$ Economics 24(4): 668-680.

Chen-Ritzo, C.-H., T. P. Harrison, A. M. Kwasnica, et al. (2005). "Better, Faster, Cheaper: An Experimental Analysis of a Multi-attribute Reverse Auction Mechanism with Restricted Information Feedback." Management Science 51(12): 1753-1762.

Davis, F. D. (1989). "Perceived Usefulness, Perceived Ease of Use and User Acceptance of Information Technology." MIS Quarterly 13(3): 319-340.

Davis, F. D., R. P. Bagozzi and P. R. Warshaw (1989). "User Acceptance of Information Technology: A Comparison of Two Theoretical Models." Management Science 35(8): 982-1003.

De Fraja, G. and J. Sakovics (2001). "Walras Retrouve: Decentralized Trading Mechanisms and the Competitive Price." Journal of Political Economy 109(4): 842-863.

DeLone, W. and E. McLean (1992). "Information Systems Success: The Quest for the Dependent Variable." Information Systems Research 3(1): 60-95.

DeLone, W. H. and E. R. McLean (2003). "The DeLone and McLean Model of Information Systems Success: A Ten Years Update." Journal of Management Information Systems 19(4): 9-30.

Dishaw, M. T. and D. M. Strong (1996). Explaining Information Technology Utilization with the Task-technology Fit Conctructs. First INFORMS Conference on Information Systems and Technology, Providence, RI, INFORMS.

Dishaw, M. T. and D. M. Strong (1998). "Assessing Software Maintenance Tool Utilization using Task-technology Fit and Fitness-for-use Models." Journal of Software Maintenance: Research and Practice 10(3): 151-179.

Doll, W. J., A. Hendrickson and X. Deng (1998). "Using Davis's Perceived Usefulness and Ease-ofuse Instruments for Decision Making: A Confirmatory and Multigroup Invariance Analysis." Decision Sciences 29(4): 839-869.

Doll, W. J. and G. Torkzadeh (1988). "The Measurement of End User Computing Satisfaction Issues." MIS Quarterly 12: 259-274.

Doll, W. J. and G. Torkzadeh (1991). "Issues and Options. The Measurement of End User Computing Satisfaction: Theoretical and Methodological Issues." MIS Quarterly 15: 5-10.

Dufner, D. (2003). "The IS Core-I: Economic and Systems Engineering Approaches to IS Identity." 12(31): 527-538.

Friedman, D. and S. Sunder (1994). Experimental Methods: A Primer for Economists. Cambridge, 
Cambridge University Press.

Galinsky, A. D., T. Mussweiler and V. H. Medvec (2002). "Disconnecting Outcomes and Evaluations: The Role of Negotiator Focus." Journal of Personality and Social Psychology 83(5): 1131-1140.

Glass, R. L., V. Ramesh and T. Vessey (2004). "An Analysis of Research in Computing Disciplines." Communications of the ACM 47(6): 89-94.

Goodhue, D. L. (1995). "Understanding User Evaluation of Information Systems." Management Science 41: 1827-1844.

Goodhue, D. L. and R. L. Thompson (1995). "Task-Technology Fit and Individual Performance." MIS Quarterly 19(2): 213-236.

Gregg, D. G., U. R. Kulkarni and A. S. Vinze' (2001). "Understanding the Philosophical Underpinnings of Software Engineering Research in Information Systems." Information Systems Frontiers 3(2): 169-183.

Hayek, F. (1945). "The Use of Knowledge in Society." American Economic Review 35(4): 519-530.

Hevner, A. R., S. T. March, J. Park, et al. (2004). "Design Science in Information Systems Research." MIS Quarterly 28(1): 75-105.

Hurwicz, L. (1973). "The Design of Mechanisms for Resource Allocation." American Economic Review 63(2): 1-30.

Hyder, E. B., M. J. Prietula and L. R. Weingart (2000). "Getting to Best: Efficiency vs. Optimality in Negotiation." Cognitive Science 24(2): 169-204.

Iivari, J. (2003). "The IS Core - VII: Towards Information Systems as a Science of Meta-Artifacts." Communications of the Association for Information Systems 12(37): 568-581.

Iivari, J. (2005). "An Empirical Test of the DeLone-McLean Model of Information System Success." The DATA BASE for Advances in Information Systems 36(2): 8-27.

ISR (2002). "Editorial Statement and Policy." Information Systems Research 13(4).

Jackson, C. M., S. Chow and R. A. Leitch (1997). "Toward an Understanding of the Behavioral Intention to Use an Information System." Decision Sciences 28(2): 357-389.

Kirkegaard, R. (2004). Auctions versus Negotiations Revisited. Working Paper. Aarhus, Department of Economics, University of Aarhus.

Kiser, L. L. and E. Ostrom (1982). The three worlds of action: A metatheoretical synthesis of institutional approaches. Strategies of Political Inquiry. E. Ostrom. Beverly Hills, CA, Sage: 179-222.

Koppius, O. and E. van Heck (2002). Information Architecture and Electronic Market Performance in Multidimensional Auctions. Erasmus Research Institute of Management. Rotterdam, Erasmus University, Rotterdam: 38.

Kumar, M. and S.I.F. (1999). Internet Auctions. IBM Research Division, T.J. Watson Research Center.

Ledyard, J. (1993). "The Design of Coordination Mechanisms and Organizational Computing." Journal of Organizational Computing 3(1): 121-134.

Legris, P., J. Ingham and P. Collerete (2003). "Why Do People Use Information Technology? A Critical Review of the Technology Acceptance Model." Information and Management 40: 191-204. 
Leskela, R. L., J. Teich, H. Wallenius, et al. (2006). Decision Support for Multi-Unit Combinatorial Bundle Auctions. Helsinki, Helsinki University of Technology.

Lucking-Reiley, D. (2000). "Auctions on the Internet: What's Being Auctioned, and How?" Journal of Industrial Economics 48(3): 227-252.

March, S. T. and G. F. Smith (1995). "Design and Natural Science Research on Information Technology." Decision Support Systems 15: 251-266.

Markus, M. L., A. Majchrzak and L. Gasser (2002). "A Design Theory for Systems that Support Emergent Knowledge Processes." MIS Quarterly 26(3): 179-212.

Maskin, E. and T. Sjöström (2002). Implementation Theory. Handbook of Social Choice and Welfare. K. J. Arrow, A. Sen and K. Suzumura. Amsterdam, NL, Elsevier Science B.V. 1: 237-288.

McAfee, R. P. and J. McMillan (1987). "Auctions and Bidding." Journal of Economic Literature 25(2): 699-738.

Mount, K. and S. Reiter (1974). "The Informational Size of Message Spaces." Journal of Economic Theory 8(1): 161-192.

Nash, J. F. (1954). "The Bargaining Problem." Econometrica 18: 155-162.

Neumann, D., M. Benyoucef, S. Bassil, et al. (2003). "Applying the Montreal Taxonomy to State of the Art E-negotiation Systems." Group Decision and Negotiation 12(4): 287-310.

Nunamaker, J. F. J., M. Chen and T. D. M. Purdin (1991). "Systems Development in Information Systems Research." Journal of Management Information Systems 7(3): 89 - 106.

Orlikowski, W. J. and C. S. Lacono (2001). "Research Commentary: Desperately Seeking the 'IT' in IT Research - A Call to Theorizing the IT Artifact." Information Systems Research 12(2): 121-134.

Palfrey, T. (2001). Implementation Theory. Handbook of Game Theory. R. J. Aumann and S. Hart. Amsterdam, North-Holland. 3.

Parkes, D. C. (2001). Iterative Combinatorial Auctions:

Achieving Economic and Computational Efficiency. Department of Computer and Information Science, University of Pennsylvania.

Pikkarainen, K., T. Pikkarainen, H. Karjaluoto, et al. (2006). "The Measuremnet of End-user Computing Satisfaction of online Banking Services: Empirical Evidence from Finland." International Journal of Banki Marketing 24(3): 158-172.

Rangaswamy, A. and K. Starke (2000). Computer-Mediated Neotiations: Review and Research opportunities. Encyclopedia of Microcomputers. A. Kent and J. G. Williams. New York, NY, Marcel Dekker. 25: 47-72.

Reiter, S. (1977). "Information and Performance in the (New ${ }^{2}$ Welfare Economics." American Economic Review 67(1): 226-234.

Roth, A. (2002). "The Economist as Engineer: Game Theory, Experimentation, and Computation as Tools for Design Economics." Econometrica 70(4): 1341-1378.

Roth, A. E. (1995). Introduction to Experimental Economics. The Handbook of Experimental Economics. J. H. Kagel and A. E. Roth. Princeton, NJ., Princeton University Press: 3-110.

Rothkopf, M. H., A. Pekec and R. M. Harstad (1998). "Computationally Manageable Combinatorial Auctions." Management Science 44(8): 1131-1147. 
Satterthwaite, M. and A. Shneyerov (2003). "Convergence of a Dynamic Matching and Bargaining Market with Two-sided Incomplete Information to Perfect Competition." Working Paper.

Satterthwaite, M. and A. Shneyerov (2006). "Dynamic Matching, Two-sided Incomplete Information, and Participation Costs: Existence and Convergence to Perfect Competition." Econometrica: in print.

Segev, A. and C. Beam. (1999). "A New Market-based Negotiation Paradigm." Retrieved http://haas.berkeley.edu/ citm/nego/newnego.html.

Shakun, M. F. (2005). "Multi-bilateral Multi-issue E-negotiation in E-commerce with a Tit-for-Tat Computer Agent." Group Decision and Negotiation 14(5): 383-392.

Simon, H. (1996). The Sciences of the Artificial. Cambridge, Massachusetts, The MIT Press.

Simon, H. A. (1986). "Rationality in Psychology and Economics." The Journal of Business 59(4): 209-224.

Smith, V. (1982). "Microeconomic Systems as an Experimental Science." American Economic Review 72(5): 923-955.

Smith, V. (1994). "Economics in the Laboratory." Journal of Economic Perspectives 8(1): 113-131.

Smith, V. (2003). Markets, Institutions and Experiments. Encyclopedia of Cognitive Science. L. Nadel. London, Nature Publishing Group. 2: 991-998.

Strecker, S. (2004). Multiattribute Auctions in Electronic Procurement - Theory and Experiment -. Economics and Business Engineering. Karlsruhe, Germany, University of Karlsruhe (TH).

Ströbel, M. and C. Weinhardt (2003). "The Montreal Taxonomy for Electronic Negotiations." Group Decision and Negotiation 12(2): 143-164.

Subrahmanian, E. and S. N. Talukdar (2004). "Engineering of Markets and Artifacts." Electronic Commerce: Research and Applications 3(4): 369-380.

Szajna, B. (1996). "Empirical Evaluation of the Revised Technology Acceptance Model." Management Science 42(1): 85-92.

Teich, J., H. Wallenius, J. Wallenius, et al. (2001). "Designing Electronic Auctions: An InternetBased Hybrid Procedure Combining Aspects of Negotiations and Auctions." Journal of Electronic Commerce Research 1: 301-314.

Thomas, C. J. and B. J. Wilson (2002). "A Comparison of Auctions and Multilateral Negotiations." RAND Journal of Economics 33(1): 140-155.

Thomas, C. J. and B. J. Wilson (2005). "Verifiable Offers and the Relationship Between Auctions and Multilateral Negotiations." The Economic Journal 115 (506): 1016-1031.

Tichy, W. F., P. Lukowicz, L. Prechelt, et al. (1995). "Experimental Evaluation in Computer Science: A Quantitative Study." Journal of Systems and Software 28(1): 9-18.

Torkzadeh, G. and W. J. Doll (1999). "The Development of a Tool for Measuring the Perceived Impact of Information Technology on Work." Omega 27(3): 327-339.

Turner, M., D. Budgen and P. Brereton (2003). "Turning Software into a Service." Computer 36(10): $38-44$.

Vahidov, R. (2006). Design Researcher's IS Artifact: A Representational Framework. First International Conference on Design Science Research in Information Systems and Technology (CD-ROM Proceedings), Claremont, CA. 
Venkatesh, V. and F. D. Davis (2000). "A Theoretical Extension of the Technology Acceptance model: Four Longitudinal Field Studies." Management Science 46(2): 186-204.

Venkatesh, V. and M. G. Morris (2000). "Why Don't Men Ever Stop To Ask For Directions? Gender, Social Influence, and Their Role in Technology Acceptance and Usage Behavior." $\underline{\text { MIS }}$ Quarterly 24(1): 115-140.

Venkatesh, V., M. G. Morris, G. B. Davis, et al. (2003). "User Acceptance of Information Technology: Toward A Unified View." MIS Quarterly 27(3): 425-478.

Walls, J. G., G. R. Widmeyer and O. A. El Sawy (1992). "Building an Information System Design Theory for Vigilant EIS." Information Systems Research 3(1): 36-59.

Wixom, B. H. and P. A. Todd (2005). "A Theoretical Integration of User Satisfaction and Technology Acceptance." Information Systems Research 16(1): 85-102.

Wolfstetter, E. (1995). "Auctions: An Introduction." Journal of Economic Surveys 10(4): 367-420.

Wolfstetter, E. (2000). Topics In Microeconomics. Industrial Organization, Auctions, and Incentives Cambridge Cambridge University Press.

Zelkowitz, M. and D. Wallace (1998). "Experimental models for validating technology." IEEE Computer 31(5): 23-31.

Zhu, K. (2004). "The Complementarity of Information Technology Infrastructure and E-Commerce Capability: A Resource-Based Assessment of Their Business Value." Journal of Management Information Systems 21(1): 167 - 202.

Zwass, V. (1996). "Electronic Commerce: Structures and Issues." International Journal of Electronic Commerce 1(2): 3 - 23. 